\title{
SOCIO-DEMOGRAPHIC DETERMINANTS; THALASSIMIC CHILDREN
}

1. DCH, FCPS

Associate Professor

Community Medicine Department

Quaid-Azam Medical College

Bahawalpur.

2. MBBS, MCPS

Associate Professor

Community Medicine Department

Bakhtawar Amin Medical College

Multan.

Correspondence Address:

Dr. Abdul Salam Malik

52- B, Medical Colony Bahawalpur,

Pakistan.

salammalik62@hotmail.com

Article received on:

11/03/2017

Accepted for publication:

15/06/2017

Received after proof reading:

$08 / 08 / 2017$

\begin{abstract}
Abdul Salam Malik', Khalil Ahmad Shahid ${ }^{2}$
ABSTRACT... Background: Thalassemic children require regular multiple blood transfusions. It leads to multiple complications such as blood born infections, iron over load (Haemosidrosis) and spleen enlargement. Thalassemia transmission to future generations can be prevented and life of thalassemic children can also be prolonged by proper devoted pre-marital and intra uterine life management and mitigation of fatal complications. Objectives: The objective of this study was to assess the socio-demographic determinants of thalassemic children. Study Design: Descriptive study. Setting: Thalassemia Centre Bahawal Victoria Hospital Bahawalpur. Period: One year from January 1, 2016 to December 31, 2016. Material and Method: Parents /guardians of 200 diagnosed children as thalassemic, who were receiving blood transfusions were selected for interview. The data was collected by Pre- designed Performa to assess sociodemographic determinants. The data was analyzed to formulate hypothesis. Results: It was found that maximum number of patients coming for blood transfusion were from 7-9 years and 10 years and above contributing $30 \%$ each while $4-6$ years were $24 \%$ showing that majority of people seeking for frequent blood transfusion service were over 4 years of age in this area. At least one thalassemic child death was disclosed by $32(16 \%)$ families. The birth order of the present thalassemic child as $2^{\text {nd }}$ one was told by $60(30 \%)$ parents. There were $72(36 \%)$ coming from distance $<20 \mathrm{~km}$ which shows maximum utility of this center by local area population. It was found that 104 (52\%) belong to poor socio-economic class. There were $188(94 \%)$ children receiving blood transfusion from teaching hospital blood transfusion center where as 100 $(50 \%)$ blood donors were unknown people. There were $104(52 \%)$ children who were never checked for Hepatitis C virus markers while $116(58 \%)$ mothers were illiterate. Regular use of iron chelating therapy was found to be $8 \%$ only. There were $128(64 \%)$ marriages proposed by parents and $72(36 \%)$ enforced by grand elders resulting $144(72 \%)$ marriages with first cousins. There were $160(80 \%)$ consanguineous marriages and $188(94 \%)$ without premarital thalassemia test. There were $142(71 \%)$ new born deliveries without prenatal thalassemia test. Conclusion: The enforced consanguineous marriages, lack of pre- marital and pre-natal diagnosis, poverty, illiteracy and lack of iron chelating agent support are the thalassemia problem exaggerating factors. Reducing magnitude of these problems can mitigate over load and socio-demographic constraints of thalassemic patients in our country.
\end{abstract}

Key word: $\quad$ Thalassemia, marriages, chelating agent, pre-marital, carrier.

Article Citation: Malik AS, Shahid KA. Socio-demographic determinants; thalassimic children. Professional Med J 2017;24(8):1170-1175. DOI: 10.17957/TPMJ/17.4043

\section{INTRODUCTION}

There are multiple blood anomalies. Thalassemia is one of these abnormal hemoglobin related pathological conditions. Iron deposition in multiple organs of these children results in multiple clinical presentations and fatal complications of thalassemia, depending upon body tissue of a system involved but anemia is the universal sign. ${ }^{1}$ Multiple blood transfusions are highly risky for blood born infections transmission such as hepatitis $\mathrm{B}$ or $\mathrm{C}$ and HIV including blood parasitic diseases. ${ }^{2}$ Iron is heavy metal and is part of hemoglobin. Iron over load can be determined by serum ferritin level measurement. Awareness about iron deposition is essential to initialize chelating therapy at the earliest to mitigate the intensity of hemosidrosis effects. ${ }^{3}$

The thalassemia major also called Betathalassemia causes more severe clinical presentations of this abnormality. It is due to the most common heterogeneous single gene inherited disorder in beta globin chain of human hemoglobin resulting in defective functional 
red blood cells. ${ }^{5}$ The condition is genetically transferred to next generations due to its carriers. However, ideal prevention carrier problem can be achieved by multi-disciplinary actions through a team and not by a single person. ${ }^{6}$ Life long multiple blood transfusions cause many behavioral problems in thalassemic children. Proper early diagnosis and intervention can mitigate this problem. ${ }^{7}$ It is estimated that there are 5 to $7 \%$ carriers in population of Pakistan. ${ }^{8}$ Anxiety, depression and conduct problems are very evident among thalassemic children. ${ }^{10}$

There is strong family bonding system in Pakistan. The marriages are not decided usually by the wish and likeness of young couples, particularly in rural areas. These are enforced commonly by family elders. Male and female new born babies are nominated by grand parents for marriage together to retain inherited properties within there families in rural areas. Similarly, consanguineous marriage is highly influenced by the elders and is common practice among residents of Arab civilization territories. ${ }^{11}$ This tradition is favorable for onward transmission and clinical appearance of thalassemia among the next generations. Forceful consanguineous marriages are too difficult to prevent and require reproductive health education programs for many decades.

\section{METHODOLOGY}

The descriptive study was carried out at thalassemia centre, Bahawal Victoria Hospital Bahawalpur which is a tertiary care teaching hospital, during the period of one year from January 1, 2016 to December 31, 2016. Total number of 6757 blood transfusions was given to all thalassemic children with average 23 transfusions daily. There were 8 to 15 newly diagnosed thalassemia major patients every month. Sample size of 200 patients both new and old was taken by purposive convenience sample method. A Questionnaire Performa was designed for "face to face" interview to assess sociodemographic determinants of these patients from their parents or guardians seeking for their blood transfusion.

Parents of patients with thalassemia confirmed, diagnosed both new and old, registered and receiving blood transfusions were selected for interview after informed consent. Foster mother or father of adopted children and parents non- willing for interview were excluded from study. Those children who were very sick taking emergency management due to thalassemia complications were also excluded because their parents or guardians were in severe mental stress. All patients who were taking blood transfusions from private blood banks/ hospitals were excluded.

Help of tetra lingual local paramedical staff and nurses was taken for translation and mitigation of language bias problems during interview. The study was carried out on self-finance bases getting no expenses from any donor organization. The help of field staff of Punjab thalassemia prevention program was taken to study and understand socio-demographic determinants of thalassemic patients and their solutions. Family pedigree drawn by field staff after thalassemia carrier screening tests was also studied where ever available. The data was collected, condensed on data master sheet and analyzed to formulate hypothesis.

\section{RESULTS}

This study revealed that maximum number of patients coming for blood transfusion were from 7-9 years and 10 years and above contributing $30 \%$ each of them. However, 4-6 years age group was very close (24\%) to the higher age patients. It has shown that people seeking for blood transfusion service for thalassemic children were more commonly after 4 years of age in this area. No death by thalassemia was reported from 148 (74\%) families, but at least one child death incidence was disclosed by 32 (16\%) families which is considerable death score among thalassemic families as shown in Table-I.

The birth order of thalassemic child as $2^{\text {nd }}$ one was told by $60(30 \%)$ parents. That means second baby has relatively more chance to be the sufferer. Similarly 72 (36\%) were coming from distance $<20 \mathrm{~km}$ which shows maximum utility of this center by local area population for blood transfusion facilities. It was found that 
socioeconomic status / financial income was inversely proportional to the number of thalamic patients in family because majority of thalassemic children, 104 (52\%) were belonging to poor socioeconomic class as shown in Table-I.

In spite of the fact that 188 (94\%) children were receiving blood transfusion from teaching hospital blood transfusion center, it was disclosed that majority of blood donors, 100 (50\%) were from unknown people which was very alarming. Treatment expenses were afforded by 192 (96\%) parents only, showing no considerable financial support from other sources as depicted in Table-l. Viral hepatitis markers are very essential for these patients but 104 (52\%) revealed that these were never checked. Maternal Illiteracy has been found to play major role for spread of thalassemia as $116(58 \%)$ mothers were illiterate. However, 76 (38\%) fathers were secondary school level literate. There were $180(90 \%)$ families having 1-5 children alive in average but regular use of iron chelating therapy among their thalassemic children was found to be $8 \%$ only, as shown on Table-I.

Marriages constraints were inquired and it revealed that $128(64 \%)$ marriages were proposed by parents and $72(36 \%)$ proposals were enforced by grand elders without like and dislike right giving to children. It is alarming constraint to control thalassemia spread because 144 (72\%) marriages were proposed within first cousins. There were 160 (80\%) consanguineous marriages providing fertile ground for thalassemia major genes expression while 188 (94\%) marriages were done without premarital thalassemia test. There were $142(71 \%)$ new born deliveries without prenatal chorionic villous biopsy test for thalassemia as shown in Table-I

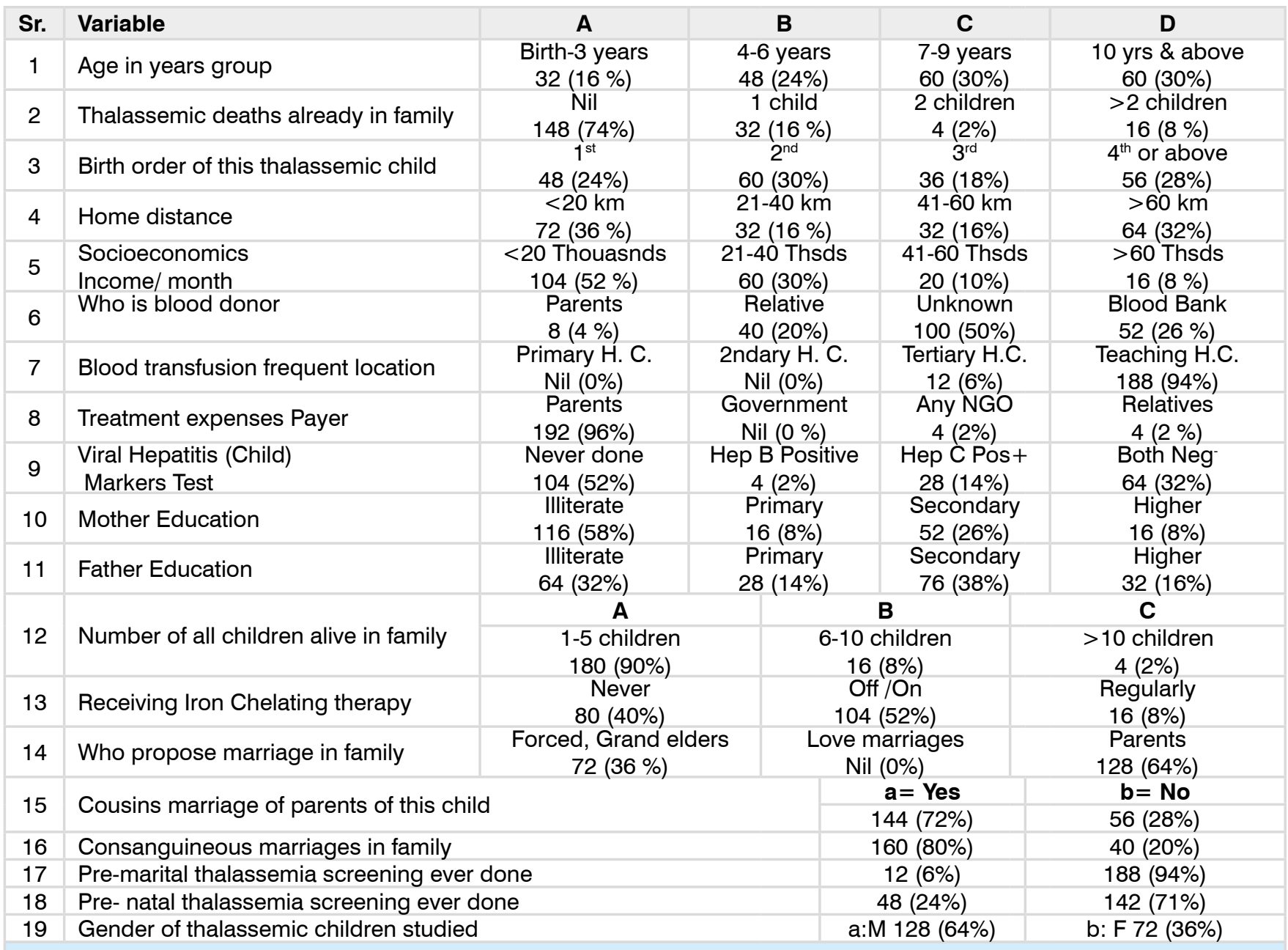

Table-l. Socio-demographic determinants of thalassemic patients $n=200$ 


\section{DISCUSSION}

Thalassemia is one of the haemoglobinopathies having different sub types. This disease is spreading with enormous speed in our area. Thalassemic children have multiple sociodemographic determinants. Iron over load (haemosidrosis) is fatal for them. All parents cannot afford chelating therapy expenses. The irregular, costly and insufficient supply problem of chelating agents, is increasing early death events of these children. The best portable infusion pump services can keep normal daily life activities of these children as depicted by Borgna- Pignatti $\mathrm{C}^{1}$ but our study revealed only $16(8 \%)$ patients who were using regular chelating therapy. There were $80(40 \%)$ patients who have never received any chelating agent. It has been quoted by Tiwari $A$ and Alisha $A^{3}$ that lack of awareness also play major role for use of chelating agent. There is urgent need of rationalization of chelating therapy.

There were 104 (52\%) patients who have never been checked for Hepatitis $C$ viral infection i.e. $\mathrm{HCV}$ status was unknown. It has been quoted in other literature ${ }^{1}$ that thalassemic patients get HCV infection commonly but our study revealed serious constraint of unknown viral hepatitis status among more than $50 \%$ cases. It was found that $28(14 \%)$ patients were suffering from known hepatitis $\mathrm{C}$ infection but another study ${ }^{2}$ have revealed that $15 \%$ children are infected with HVC which is very close to our finding.

Our study have revealed that pre-marital and prenatal screening for thalassemia detection were not done by 188 (94\%) and 142 (71\%) parents respectively. It is major socio-demographic problem responsible for rapid up surge of thalassemia spread in our area. Similarly Petrou $\mathrm{M}^{4}$ has also described that there is a little use of prenatal diagnosis in communities where high incidence rate is noted. We have found very strong preference of consanguineous marriages $(80 \%)$ among first cousins $(72 \%)$. It is very unfortunate that marriages proposed by parents were $64 \%$ and forced by grand elders were noted among $36 \%$ families. The like or dislike right of children has no value among these families. It is mentioned in another study ${ }^{4}$ that $98 \%$ of at risk couples who were detected to be thalassemic carrier very close to marriage ceremony proceed to marry.

There were 104 (52\%) families from poor socioeconomic class having thalassemic children. It is major socio-demographic problem because parents of more than half of thalassemic children cannot afford costly therapeutic abortion and chelating therapy due to limitation of their resources. It is concordant with studies of other researchers $^{4}$ also. The gender of thalassemic children was inquired. It was found that there were 128 (64\%) males and 72 (36\%) females which correlate very closely with another study 8 describing males to be $58.2 \%$ and females $42.8 \%$ cases. It may be most probably due to reproduction of male child preference for multiple reasons.

Our study revealed 116 (58\%) mothers to be illiterate. However, Riaz $\mathrm{H}$ et $\mathrm{el}^{8}$ described $78.8 \%$ cases where education of care taker was below $10^{\text {th }}$ grade level which is considerably higher than our finding. We have found father education more than $10^{\text {th }}$ grade to be among $76(38 \%)$ cases. Blood transfusions and all other diagnostic tests services should be decentralized. It will decrease the cost of treatment and family harassment in travelling as mentioned by Malik $S$ and Chatterjee $\mathrm{C}^{9}$ also.

In families where access is poor, new health policies must be developed to tackle population diversities towards very high thalassemia prevalence which is emphasized by Szezepura $\mathrm{A}^{12}$ also. Thalassemia control and prevention require joint multi-directional comprehensive efforts with full cooperation and participation of state health services and families.

\section{LIMITATIONS OF STUDY}

1. The sample size is relatively small.

2. Blood transfusion based HIV transmission to thalassemic children has not been included.

3. Multiple social communities of different countries are required to make findings more 
comprehensive.

\section{CONCLUSION}

Pre-marital carrier detection and therapeutic abortion of thalassemia major cases is essential to prevent this disease. Lack of prevention of enforced consanguineous marriages through influential local political and religious personals, poverty, illiteracy and lack of iron chelating agent support are the thalassemia problem exaggerating factors. Reducing these problems can mitigate thalassemia over load to very low level in our community.

\section{RECOMMENDATIONS}

Pre-marital thalassemia carrier's identification and prenatal intra uterine diagnostic services by the state health departments through thalassemia prevention program free of cost is essential. It is to identify thalassemia before appearance in the future generations and alert the parents to strengthen community awareness.

Therapeutic abortion of confirmed intrauterine thalassemia major fetus and pre-marital community intervention action with consent of parents, elders and influential local political or religious community leaders must be emphasized to decrease this rapidly expanding disease in our community. Expenses for the purpose may be paid by the local government.

Consanguineous marriages may be discouraged slowly through constant reproductive health education and different effective psycho-social strategies.

Iron chelating tablets and injections may be provided by health care delivery center free of cost to incorporate and register the maximum number of thalassemic children. Removal of burden of costly treatment from shoulders of thalassemic children's parents is highly recommended.

Copyright( 15 June, 2017.

\section{REFERENCES}

1. Borgna-Pignatti $C$, The life of patients with thalassemia major. Thalassemia Haematologica. 2010 Mar; 95(3): 345-348.

2. Shah N, Mishra A, Chauhan D, Vora C, Shah NR. Study on effectiveness of transfusion Program in thalassemia major patients receiving multiple blood transfusions at a transfusion center in Western India. Asian J Transfus Sci. 2010 Jul; 4(2): 94-98.

3. Mishra AK, Tiwari A. Iron overload in Beta Thalassemia Major and Intermediary Patients. Maedica (Buchar). 2013 Sep; 8(4): 328-332.

4. Petrou M. Screening for beta thalassemia. Indian $\mathrm{J}$ Hum Genet. 2010 J Hum Genet. 2010 Jan-Apr; 16(1): 1-5.

5. Christopher AF, Kumari A, Chaudhary S, Hora S, Ali Z, Agrawal SC. Unique pattern of mutations in B-thalassemia patients in Western Uttar Pradesh. Indian J Hum Genet. 2013 Apr-Jun; 19(2): 207-212.

6. Bandyopadhyay U, Kundu D, Sinha A, Banerjee K, Bandyopadhyay R, Mandal T, Ray D. Conservative management of Beta-thalassemia major cases in the sub-division level hospital of rural West Bengal, India. Nat Sci Biol Med. 2013 Jan-Jun; 4(1): 108-112.

7. Hongally C, Benakappa AD, Reena S. Study of behavioral problems in multi-transfused thalassemic children. Indian J Psychiatry. 2012 Oct-Dec; 54(4): 333336.

8. Riaz H, Riaz T, Khan MU, Aziz S, Ullah F, Rehman A, et al. Serum Ferritin levels, Socio-demographic factors and desferrioxamine therapy in multi-transfused thalassemia major patients at a government tertiary care hospital of Karachi, Pakistan. BMC Res Notes. 2011; 4: 287.

9. Malik S, Chatterjee C, Mandal PK, Sardar JC, Ghosh P, Manna N. Expenditure to treat thalassemia: An experience at a Tertiary Care Hospital in India. Ran J Public Health. 2010; 39(1): 78-84.

10. Shaligram D, Girimaji SC, Chaturvedi SK. Psychological Problems and Quality of life in children with thalassemia. Indian J Pediatr. 2007; 74 (8): 727-730.

11. Tadmouri GO, Nair P, Obeid T, Ali MT, Khaja NA, Hamamy HA. Consanguinity and reproductive health among Arabs. Reproductive Health 2009, 6:17 doi: 10.1186/1742-4755-6-17.

12. Szezepura A. Access to health care for ethnic minority populations. Postgrad Med J. 2005; 81: 141-147. 


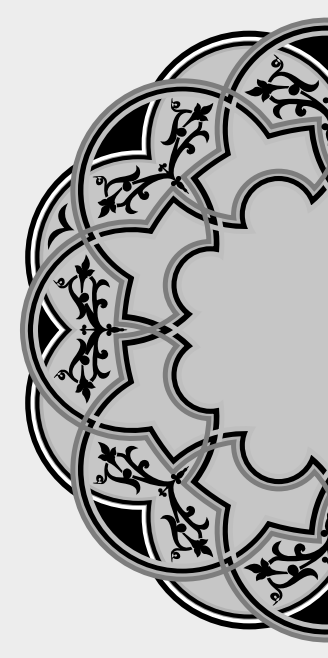

\title{
"Being defeated is often a temporary conditions; giving up is what makes it permanent."
}

\author{
Unknown
}

\begin{tabular}{|c|c|c|c|}
\hline \multicolumn{3}{|c|}{ AUTHORSHIP AND CONTRIBUTION DECLARATION } \\
\hline Sr. \# & Author-s Full Name & Contribution to the paper & Author=s Signature \\
\hline 1 & Abdul Salam Malik & 1st Author & \\
\hline & & & \\
\hline
\end{tabular}

